Part of Journal of Research of the National Bureau of Standards, Volume 16, May 1936

\title{
A MODIFIED ACCELERATED WEATHERING TEST FOR ASPHALTS AND OTHER MATERIALS
}

\author{
By O. G. Strieter ${ }^{1}$ and H. R. Snoke
}

\begin{abstract}
A modified method for testing asphalts and similar complex materials by accelerated weathering is described.

A variety of materials are shown to exhibit the same type of chemical changes when exposed to the accelerated weathering cycle. The experiments show that the weathering process gradually transforms these materials into products that are largely soluble in water, and that these soluble products may be collected quantitatively for examination and identification. The function of light and oxygen in the weathering process is explained, and data are given to show that the products of accelerated weathering are similar to those obtained in outdoor exposures. New applications of accelerated weathering are suggested.
\end{abstract}

\section{CONTENTS}

I. Introduction

I. Introduction _...

II. Weathering of asphalts and other materials 482

III. The function of light and oxygen in weathering

IV. The modified accelerated weathering cycle

V. Applications of the modified accelerated weathering cycle_..... 484

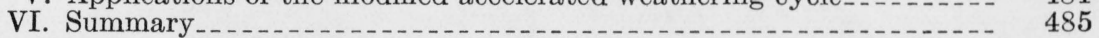

\section{INTRODUCTION}

The weathering of asphalts has been studied by a number of investigators, and the fact that exposure to sunlight renders asphalts insoluble in certain organic solvents is well established, having at one time been extensively used in photography. ${ }^{2}$ That the products formed by the weathering of asphalts are largely soluble in water is not widely known ${ }^{3}$ and has not been previously investigated.

It has been shown in a previous paper ${ }^{4}$ that asphalts behave similarly when exposed to accelerated and to outdoor weathering. However, in previous tests conclusions were drawn only from the appearance of the weathered asphalt, since no provision was made to recover any of the products of weathering.

\footnotetext{
${ }_{1}^{1}$ Research Associate at the National Bureau of Standards, representing the Asphalt Shingle and Roofing Institute.

${ }_{2}^{2}$ Herbert Abraham, Asphalts and Allied Substances, 3d ed., p. 835 (D. Van Nostrand Co., New York, 1929).

${ }^{3}$ See p. 838 of reference 2

4 O. G. Strieter, BS J. Research 5, 247 (1930) RP197.
} 


\section{WEATHERING OF ASPHALTS AND OTHER MATERIALS}

For the purpose of this investigation, the following types of materials were selected: asphalt $\mathrm{A}$, of softening point $220^{\circ} \mathrm{F}$; asphalt $\mathrm{B}$, of softening point $160^{\circ} \mathrm{F}$; and $\mathrm{C}$, asphalt-saturated felt and smoothsurfaced asphalt-prepared roofing.

Material A was surfaced on aluminum plates to a thickness of 0.025 inch and subjected to a cycle consisting in 19 hours exposure to light and heat from a carbon-are lamp and 5 hours immersion in distilled water, at room temperature, until the water was colored a decided brown. Material B was an asphalt that had been exposed outdoors in a location of abundant sunlight, relatively high humidity, and practically no rainfall; and material $\mathrm{C}$ had been exposed outdoors at the National Bureau of Standards for a period of 7 years.

Materials $B$ and $C$ were immersed in water and the solutions filtered to remove any suspended matter. These solutions, and that obtained from material $\mathrm{A}$, were evaporated to dryness and the residues dried at $105^{\circ} \mathrm{C}$. These residues were quite similar in appearance, being resin-like and brittle, black in color (brown when pulverized or in thin layers), and with an odor resembling caramel or burnt sugar.

Each of these products was found to be acid and to reduce Fehling's solution. The most concentrated solution which could be read with a polariscope was $200 \mathrm{mg}$ of substance in $10 \mathrm{ml}$ of water in a tube $20 \mathrm{~mm}$ long. No rotation could be detected. The acidity was determined by titration with $N / 10$ alkali, using litmus as indicator. The acidity is expressed (table 1 ) as milliliters of $N / 10$ alkali necessary to neutralize $1 \mathrm{~g}$ of water-soluble substance. The reducing power was determined quantitatively by the method of Allihn and the values given in table 1 represent the reducing power expressed as dextrose.

TABLE 1.-Reducing power and acidity of water-soluble material

\begin{tabular}{|c|c|c|c|}
\hline Material & Method of exposure & $\begin{array}{l}\text { Reducing } \\
\text { power in } \\
\text { terms of } \\
\text { dextrose }\end{array}$ & $\begin{array}{l}\text { Acidity } \\
N / 10 \\
\text { alkali }\end{array}$ \\
\hline $\begin{array}{ll}\mathrm{A} \\
\mathrm{B} \\
\mathrm{C}\end{array}$ & $\begin{array}{l}\text { Accelerated cycle } \\
\text { Outdoors } \\
\text { Outdoors }\end{array}$ & $\begin{array}{rr}\% & 8 \\
9 \\
\\
& 10\end{array}$ & $\begin{array}{lr}\mathrm{ml} / \mathrm{g} & \\
& 37 \\
9 \\
15\end{array}$ \\
\hline
\end{tabular}

The reducing substance was found to be precipitated by the addition of an excess of basic lead acetate solution. The excess of lead in the clear filtrate from this solution was precipitated with a minimum amount of ammonium oxalate and this filtrate produced only a very slight reduction of Fehling's solution. The basic lead precipitate obtained above was then decomposed by hydrogen sulphide and the aerated filtrate was found to reduce Fehling's solution strongly. Such behavior points to the presence of ketone acids in the water-soluble material.

The authors are indebted to D. H. Brauns of the Polarimetry Section at the National Bureau of Standards for the examination of the asphaltic residues described above. 
A sample of asphalt (approximately $6 \mathrm{~g}$ ), surfaced on an aluminum panel to a thickness of 0.025 inch and alternately exposed to light from the carbon-are lamp and immersed in water for 24-hour periods, showed a loss in weight of $0.2070 \mathrm{~g}$ after 668 hours of light exposure. The water in which the asphalt was immersed yielded $0.1910 \mathrm{~g}$ of residue. The fact that the loss in weight of the asphalt is nearly the same as the amount of water-soluble product recovered is not necessarily significant.

Bleached cotton cloth, wool cloth, and rubber (in sheet form) were also treated by alternate exposure to light and heat from the carbonarc lamp and immersion in distilled water, the cotton and wool cloths being treated before exposure with organic solvents to remove waxes. Resin-like substances which were brittle, acid to litmus, and had a caramel odor were obtained by evaporating these water solutions. They were somewhat lighter in color than those obtained from the asphaltic materials, and, except that obtained from the wool cloth, reduced Fehling's solution.

The extent to which these materials are converted into watersoluble products by the accelerated weathering action has not been determined. However, from the observations thus far made there is no indication that the rate of weathering decreases with time or that the nature of the reactions involved in weathering changes. While the solutions in which the test specimens are immersed are uniformly clear, it is apparent that small quantities of unweathered material are present, so that the residues obtained by evaporating the solutions may not completely redissolve after drying.

\section{THE FUNCTION OF LIGHT AND OXYGEN IN WEATHERING}

To determine the function of light and oxygen in the weathering of asphalts the following experiments were devised. Asphalt (softening point $105^{\circ} \mathrm{C}$ ) was placed in two $U$-tubes with $5 \mathrm{ml}$ of freshly boiled distilled water in each. The asphalt was spread over approximately half of the inside surface of each neck of the tubes and was kept far enough from the bottom that it was not in contact with the water. In one tube the air was replaced with oxygen and in the other with carbon dioxide. The tubes were tightly stoppered and exposed to light from the carbon-arc lamp, being so arranged that light from the lamp passed through the uncovered sections of the tubes to the exposed asphalt surfaces. After light periods totaling 25 hours, moisture condensed in small droplets on the cooled surface of the asphalt exposed to oxygen. On washing the asphalt surface, the water was colored slightly yellow. The other tube, exposed and treated exactly as the one above, showed no droplets condensed on the surface of the asphalt and no color in the water. These exposures were continued for 370 hours, the tubes being cooled to room temperature and the surfaces of the asphalts washed with the water in the tubes once each day. At the end of this period the surface of the asphalt exposed to oxygen was dulled and covered with minute hair cracks or checks, and was readily wetted by the water, which was colored a decided yellow. The surface of the asphalt exposed to carbon dioxide was also dulled, but to a lesser extent, and showed surface lines in irregular patterns. The surface was not wetted 
when washed with the water, the water was not discolored, and droplets were not condensed on the surface of the asphalt on cooling. The water was taken from the tubes at the end of this exposure, the tubes thoroughly washed with distilled water, and the original water and washings combined and evaporated to dryness, dried in an oven at $105^{\circ} \mathrm{C}$ for two hours and weighed, giving residues as follows:

Tube containing oxygen

Tube containing carbon dioxide

A similar tube was prepared with the same asphalt and an atmosphere of oxygen, and exposed for 370 hours at a temperature of $80^{\circ} \mathrm{C}$ in the dark. After 24 hours droplets condensed on the surface of the asphalt on cooling, but at the end of the exposure the surface of the asphalt was slightly dulled. The dried residue obtained from this water weighed $0.0023 \mathrm{~g}$.

These experiments show that both light and oxygen are necessary for the production of water-soluble products. Other investigators ${ }^{5}$ found that oxygen was necessary in the presence of light to form products insoluble in benzene, chloroform, and similar solvents, but thought that the oxygen acted as a catalyst in the formation of more complex compounds insoluble in organic solvents. However, these observations show that oxidation products soluble in water are formed.

\section{THE MODIFIED ACCELERATED WEATHERING CYCLE}

The accelerated weathering test for asphalts mentioned above (section II, footnote 4) consists in exposing the material under test alternately to light and heat from a carbon-arc lamp, a period of refrigeration, and a period during which water is forcefully sprayed on the surfaces that have been exposed to the light. In this modified test, immersion in distilled water, at room temperature, for a period of 4 to 5 hours, is substituted for the water spray, and the refrigeration period is omitted. The progress of weathering may be followed quantitatively by evaporating the water solution at regular intervals (after 10 or 15 cycles), and drying and weighing the residue.

\section{APPLICATIONS OF THE MODIFIED ACCELERATED WEATHERING CYCLE}

It is not expected that this modified accelerated weathering cycle will replace the previous cycle which has been adopted as a standard by a number of users. However, it should prove a valuable research tool in the investigation of many practical problems in which weathering is involved, for example, the effect of antioxidants in such materials as asphalt and rubber and of mineral fillers in asphalts, or in the study of the adhesion of asphalt to mineral granules, important in roofing and road work. It may be of value in studying such complex materials as asphalts, coal, rubber, cotton, starch, wood, or wool, and the changes that occur in these materials during natural deterioration.

5 Paul Gödrich, Beiträge zur Chemie der Asphalte mit besonderer Berücksichtigung ihrer photochemischen Eigenschaften, Monatsh. Chem. 36, 535-548 (1915), also Ueber die Ursachen des Ausbleichens der Asphaltgesteine, by Edmund Graefe, Asphalt Teer Strassenbautech. 32, 625 (1932). 


\section{SUMMARY}

1. The previously described "accelerated weathering cycle" for asphalts, consisting in alternate exposure to an are light, refrigeration, and washing with a spray, has been modified by omitting the period of refrigeration, and by dipping the specimen in water instead of spraying. The wash water is then examined for soluble organic products.

2. Chemical examination of the water-soluble products obtained by weathering asphalts showed the presence of acid and ketone groups. Cotton, rubber and wool treated in the same manner gave water-soluble products similar in appearance and odor to those from asphalt, and which were acid and, with the exception of that obtained from the wool cloth, reduced Fehling's solution.

3 . Tests are described which show that the formation of the watersoluble materials from asphalt depends on exposure to light and the presence of oxygen.

4. Possible applications of accelerated weathering followed by the examination of the soluble products are suggested, including the study of the function and effectiveness of antioxidants. The examination of the soluble products of weathering may also throw light on the composition of the parent materials.

The authors express their appreciation to W. Harold Smith of the Bureau's Section of Organic Chemistry, who prepared the rubber samples for test; to E. H. Berger of the Johns-Manville Corporation, New York City, who furnished asphalt B.

Washington, January 6, 1936. 